\title{
THE
}

\section{Reforming American Higher Education: The University of Rhode Island International Engineering Program}

John M. Grandin

University of Rhode Island, grandin@uri.edu

Sigrid Berka

University of Rhode Island, sigrid_berka@uri.edu

Follow this and additional works at: https://digitalcommons.uri.edu/ml_facpubs

The University of Rhode Island Faculty have made this article openly available.

Please let us know how Open Access to this research benefits you.

This is a pre-publication author manuscript of the final, published article.

Terms of Use

This article is made available under the terms and conditions applicable towards Open Access Policy Articles, as set forth in our Terms of Use.

\section{Citation/Publisher Attribution}

Grandin, John and Sigrid Berka. "Reforming American Higher Education: The University of Rhode Island International Engineering Program." ADFL Bulletin, vol. 43, no. 1, 2014, pp. 23-44. http://dx.doi.org/ 10.1632/adfl.43.1.23

Available at: http://dx.doi.org/10.1632/adfl.43.1.23

This Article is brought to you for free and open access by the Modern and Classical Languages and Literatures at DigitalCommons@URI. It has been accepted for inclusion in Modern and Classical Languages and Literatures Faculty Publications by an authorized administrator of DigitalCommons@URI. For more information, please contact digitalcommons-group@uri.edu. 


\title{
Reforming American Higher Education: The University of Rhode Island International Engineering Program
}

\author{
John Grandin and Sigrid Berka \\ University of Rhode Island
}

\section{Preface:}

The goal of this paper is to explore how American higher education may be better adapted to the needs of today's global society by means of a more integrated curriculum, one that rigorously partners the "hard skills" of math, the sciences, and engineering (the STEM and professional disciplines) with those supposedly "softer" ones derived through the arts and humanities. The authors believe that students will be better prepared for the challenges of the contemporary workplace through an education equally grounded in the sciences and the arts, including the study of varied sets of value systems, by pursuing dual degrees across those disciplines. Having pioneered one such effective and well-known model for the internationalization of engineering education, the five year dual degree (BA/BS) International Engineering Program (IEP) at the University of Rhode Island, Berka and Grandin propose the marriage of engineering and language/culture as a model or template for a meaningful and productive partnership between science and technology, the humanities, and society as a whole, potentially adaptable to all comprehensive institutions of higher education and to a broad range of disciplines. As the United States seeks answers to a growing crisis of cost and relevance in higher education, therefore, the IEP will be presented here as an inspiration and a model for much needed reform, made possible by the creative reorganization and integration of subject areas which formerly went their separate ways, but benefitted enormously by finding their common ground.

The IEP model demonstrates the extent to which such an integrated curriculum relies on partnerships, not only across the disciplines within academia, but also partnerships between the academy and both the private and public sectors, between U.S. universities and institutions abroad which have themselves developed effective and innovative systems of higher education and provide significant competition, yet also inspiration to our own.

The IEP, which provides young engineers with a broader and more liberal education, including cross-cultural understanding and communication skills, evolved from an unusual partnership between technology and the humanities and focuses on the acquisition of second language and cross-cultural communication skills, thereby preparing its students for careers in the global workplace. The authors hope that a discussion of the International Engineering Program, its founding, its development, its cost-effective character, and its outcomes, will inspire the creation of further such partnerships. 


\section{American Higher Education in Crisis}

For the first time in American history, parents, educators, private and public sector leaders, and students are beginning to doubt the value of a university education. Charges have been leveled, for example, that students today are spending substantially less time on academics than their predecessors and are making little progress during their undergraduate years in their ability to read, write, speak, or think analytically and critically. ${ }^{1}$ Others have argued that college is burdening young people with lifelong debt to the degree that it is stifling their creativity and freedom to innovate. ${ }^{2}$ Companies are lamenting that higher education is not coordinating their educational programs with the real needs of the workplace. Parallel to this skepticism and perhaps in part because of it, both federal and cashstrapped state governments are pulling back from long-standing financial commitments to higher education. The State of Rhode Island, for example, provides $47 \%$ less state support per student in 2012 than in $2002^{3}$ and now covers less than $10 \%$ of the overall funding required to keep the university afloat and competitive. Given that the difference can only be made up by an increase in tuition, the resulting sticker prices for a college education are shocking today, whether at a state-supported university like URI or a private institution, and the end of the increases seems nowhere in sight. The financial sacrifice for a college degree might be deemed acceptable if graduates could be guaranteed a position appropriate to their education, but a high percentage, perhaps even over one-half of recent college graduates is unemployed or underemployed, ${ }^{4}$ while saddled with enormous debt, the total of which now surpasses one trillion dollars. ${ }^{5}$

The prospect of lifelong student loan debt is, by itself, sufficient to give pause to any young person considering a college education. Without assurance of a decent wage and constant employment, prospective students fear joining the 5.9 million former students who have defaulted on their student loans and are being pursued by the Department of Education and/or its collecting agents. ${ }^{6}$ They also know or

\footnotetext{
${ }^{1}$ See, for example: Arum, Richard and Roksa, Josipa, Academically Adrift: Limited Learning on College Campuses, (University of Chicago Press, 2011), and Vedder, Richard and Denhart, Matthew, Ten Principles of Higher Education Reform, Heartland Institute, March 10, 2011.

${ }^{2}$ In response to this concern, the Thiel Foundation, for example, awards $\$ 100,000$ stipends to bright young persons who choose to pursue their own ideas independently rather than attend a college or university.

${ }^{3}$ Providence Journal, Report: URI in Peril as State Funding Erodes, October 1, 2012.

${ }^{4}$ The Atlantic (April 23, 2012), with Associated Press, reports that over 50\% of recent college graduates are unemployed or underemployed. See:

http://www.theatlantic.com/business/archive/2012/04/53-of-recent-college-grads-are-jobless-orunderemployed-how/256237/

${ }^{5}$ New York Times, A Generation Hobbled by the Soaring Cost of College, May 12, 2012

${ }^{6}$ New York Times, Debt Collectors Cashing in on Student Loans, September 8, 2012
} 
will soon learn that the student loan system is unforgiving. It has no statute of limitations, and there is little hope for relief from a collection agency that can attach wages, Social Security payments and tax refunds, and ultimately destroy credit ratings. Granted, the interest rate is favorable, but, as has been recently shown, its generosity is contingent upon the mood of Congress which can change in any given year.

Despite such doubts and anxieties, young people are being told that we live in a knowledge economy and that they must have higher education to have any hope of staying at least even with their parents' standard of living. While being pushed by their families and guidance counselors, therefore, high school students are aggressively courted by colleges, universities, technical institutes, and others with the promise of cutting edge academic programs and a range of expected amenities such as luxury dormitories, fancy dining options, glitzy student centers, and modern workout facilities, all of which are, of course, being financed by the students themselves, their parents, and their college loans.

As a nation we continue to brag that we have the best universities in the world. Yet, when compared with counterparts around the globe, we find a far greater commitment to higher education in other countries, as evidenced by more substantial state financing, concomitantly less direct cost to the students, the most modern infrastructure and often higher standards. A quick look at China, for example, reveals dozens of universities with totally new campuses, state-of-the-art learning and research facilities, and very high percentages of students graduating in the fields that the nation will need to compete in a global economy, e.g., science and engineering. When compared to U.S. universities, the focus in Europe, India, China, and elsewhere is far more on engineering and science, with less concern about plush dormitories and athletics. As pointed out by Charles Vest, President of the National Academy of Engineering and former President of MIT, "across Asia more that 21 percent of the students are graduating in engineering fields \{with another $12 \%$ in the sciences $\}$. Across Europe, just under 12 percent of recent graduates are engineers. In the U.S. 4.5 percent. We are at the bottom of the list in this metric." 7

\section{Signs of Reform}

Calls for reform and innovation in American higher education are becoming commonplace, and even sometimes frantic. In the summer of 2012, for example, the Board of Visitors overseeing the University of Virginia became impatient with President Teresa Sullivan's pace of change, and fired her, even though she was popular and had been on the job for less than two years. Consisting mainly of wealthy realty developers, hedge fund managers, and other business people, the Board expected a dynamic vision in the face of a crisis highlighted by shrinking

\footnotetext{
${ }^{7}$ NAE 2011 Annual Meeting, President's Address, http://www.nae.edu/Activities/Events/AnnualMeetings/19611/53074.aspx
} 
state financial support. They wanted quick action to eliminate "marginal" departments like German and classics, to increase the number of online courses, and invest the limited resources to build a curriculum more focused on real world needs. It is a sign of the uncertainty and panic associated with these issues that the Board of the University of Virginia, facing a huge outcry from students, faculty, and alumni, reversed their decision and reinstated Sullivan as quickly as they had fired her.

Other reformers are offering alternatives to a traditional college degree. As mentioned above, the Thiel Foundation offers $\$ 100,000$ grants to bright young people to pursue their own innovative ideas rather than be sidetracked by attending a college or university. Reflecting another approach, Siemens Corporation has introduced the German apprenticeship model at its North American facilities, designed to prepare bright young people for careers with their company beginning right after high school. As reported by National Public Radio, ${ }^{8}$ high school grads in North Carolina, who had always planned on college, have the opportunity to join Siemens as interns where they are trained by the company in cooperation with the local community college. Less interested in college graduates per se, Siemens is providing these young interns with the skills needed for careers with their company at the manufacturing and technician level. The apprentices, and probably their parents too, feel that this program is a far better and more secure investment of their time and money than a bachelor's degree at a college or university. After all, when they complete this course of study and training, they will have a job with a major global corporation.

Given the high cost of an undergraduate degree and the high unemployment of graduates, those who do opt for college are becoming much more deliberate and pragmatic about their choices of major and have thus in their own way become reformers themselves. Fearing unemployment, students are shying increasingly away from fields that do not promise a job, such as English, history, philosophy, art history, and classics. Even at Yale University, which has always been a bastion for the humanities, undergraduate enrollments in this area have fallen from 19,250 in 2000-2001 to 14,604 in 2010-2011. Course enrollments in English, for example, were down from 3248 to 2595 , and in history from 4448 to $2259 .^{9}$ It is not surprising, therefore, when cash-strapped administrators do not hire replacements for retirees in these fields, or try to find ways to reinvigorate departments with falling enrollments. The students are looking for programs that will open doors, enable them to pay off their loans, and assure a satisfying career.

We agree with the need to sound an alert in the United States regarding higher education. We need to prepare our students more strongly, deliberately, and realistically for the ever-changing workplace of the $21^{\text {st }}$ Century, and we need to

\footnotetext{
${ }^{8}$ NPR, July 26, 2012, A Different Road to Work, Bypassing College Dreams

${ }^{9}$ Yale Daily News, Antonia Woodford, Humanities Face Identity Crisis, April 18, 2012
} 
do this without saddling our students with enormous debt. We need to consider carefully what skills are needed for successful careers in today's global workplace, and we need to promise our students a clear return on their investment. This means keeping pace with the highest standards, which are now set at a global level, and focusing more on the STEM disciplines needed to guarantee our nation's ongoing reputation for innovation, and it means finding ways to support our students financially. We also agree with critics that drastic steps will be required to adapt our institutions to today's realities, especially given the limited resources available, and the innate resistance to change longstanding educational traditions. We strongly disagree, however, with those who would drop everything of a nonprofessional nature like classics and German and educate solely scientists and engineers. Such a step would be short-sighted. America does indeed need more engineers, but the complexities of life in the $21^{\text {st }}$ Century demand that all students, including the engineers and those from other STEM disciplines and professional school programs, be broadly and liberally educated. This will mean that the humanities must not only be retained, but also given an expanded and modified role.

\section{The Role of the Liberal Arts}

In his blog, of June 4, 2012, ${ }^{10}$ President David Dooley of the University of Rhode Island defended a liberal arts education, arguing that "the skills of critical reading and thinking, strong writing, and effective presentation are essential in practically any career. The ability to learn continuously, to teach oneself, is also more important than ever. Creativity, a strong work ethic, self-discipline, and teamwork have always been, and will continue to be, keys to success." Dooley argues that these qualities are essential markers of the liberally educated person, that these can likewise "be the foundation for success after college," and that many great leaders and professionals have backgrounds in the arts and humanities.

While agreeing with Dooley that these outcomes of a liberally educated person are critical for success in a competitive global workplace, we must also face the reality that a high percentage of graduates with majors in the arts and humanities are struggling to find their place in the workforce, and often end up unemployed or taking jobs for which they need no higher education, e.g., as bar tenders or waitresses. Many are forced to move back home with mom and dad to make ends meet financially. It is easy to pass this problem off as the unfortunate result of a temporarily bad economy, arguing that it will soon be better. After all, this would mean there is no cause for alarm and that we can and should maintain the status quo.

Unfortunately there is a lot of evidence that the job market for the average college graduate will not substantially improve in the coming years. Things might seem better in a given year, but we all live with the fact that any boom times in the United States will depend upon corresponding booms in the Far East, Latin

${ }^{10}$ http://presidentdooley.blogspot.com, June 4, 2012 
America, the European Union and elsewhere across the globe. As a result of shakiness and long-term challenges in this new interconnected economy, jobs will be tight except possibly for those who have paid attention to the very latest trends and technologies in the global marketplace. There are jobs associated with alternative energy, nanotechnology, biomedical technology, advances in information science, and other fields tied largely to science and engineering. Indeed we hear from employers that there are lots of positions open, but that the great majority of applicants do not qualify.

We in higher education need to pay more attention to the employability of our grads, especially if we want to contribute to regional and national economic development, not to mention keeping our lecture halls full, enabling parents and future students to pay for that which we provide, and, above all, ensuring our students fulfilling career opportunities. But this does not mean that we should drop majors such as philosophy, classics or German from our offerings in favor of more courses in topics such as solar power. It does mean, however, that we should be brutally honest with our foreign language or philosophy majors about what it is that such a major provides and what prospects a major in the humanity fields might have for a future career. And we need to ask how and in what context the philosophy or any other liberal arts major makes sense, and whether the changing times require a realignment or reorganization of what we teach, how we teach, and to whom.

As former philosophy and literature majors ourselves, we, the authors of this paper, would argue that the study of classically humanistic fields provides an important path toward acquisition of the goals President Dooley has described in his blog. Learning to read carefully and critically, learning to think analytically, to define problems, to understand and care about values, learning to appreciate different perspectives, to communicate in other languages, learning to communicate across national and cultural borders, gaining an overview of thought in different historical periods, learning to write carefully and clearly are all of utmost importance for our students regardless of long-term discipline and career goals. These are important learning goals which accrue from a good liberal arts education, and less so from a purely technical or professional education. These skills are all important traits of an educated person today.

Furthermore, one need only consider the enormous problems facing our society today to cast doubt on an education ignoring the benefits of the liberal arts. The global financial system, for example, appears to be run by very smart, welleducated people who have been able to create and propagate ground-breaking, and enormously complicated new investment strategies. Underlying the latter, however, is an apparent desire, first and foremost, for personal gain at levels never imagined before, and a total lack of concern for the long-term health of their organizations or people outside of their immediate milieu, or even of their very clients. Such strategies created the real estate bubble, took advantage of millions of unsuspecting would-be homeowners, and led to the global market collapse in 2008, 
from which we are all still suffering today. Consider other realms such as the pharmaceutical industry. In 2012, the highly respected GlaxoSmithKline Corporation was forced to admit that it had aggressively marketed a new drug to treat depression in children, for whom it had not been approved. Regional representatives used lavish accounts to provide cooperating physicians and psychiatrists with trips to Hawaii, golf lessons, fishing trips, and basketball tickets, thus building demand for the very profitable product. The brashness of this policy resulted in a shocking $\$ 3$ billion fine. Similar scandals have been in the news regarding Pfizer and Johnson \& Johnson.

Even though it would be naïve to argue that a humanistic education guarantees higher professional standards and less greed in the marketplace, there is much to be said for a professional education supplemented by rigorous exposure to the arts and humanities. The engineer who studies language and culture and spends a year abroad, the pharmacist who studies comparative thought and ethics, and the accounting major who studies Shakespeare are bound to be more thoughtful as they enter the workplace and make the decisions impacting the future of their own culture. On the other hand, the same may be said for the English literature major who at least minors in a science or technology discipline, the German major who studies international business, or the philosophy major who studies genetics.

Humanists might argue that we are speaking of the humanities here almost as a supplement to the STEM and/or professional school disciplines and are thus cheapening or weakening them as disciplines unto themselves. On the contrary, we are arguing that there is a greater need for humanities education than ever before and that it must play a role for all students, not just its disciplinary majors. We in no way wish to disavow the humanities as independent areas of intellectual pursuit, but the realities of a technologically driven global society demand a reconsideration of the roles of the humanities. To be liberally educated today demands significant background in both humanistic and technical endeavors.

These considerations are not intended solely for the students in the STEM disciplines, but also carry clear implications for the student majoring in the humanities. Just as we argue that engineering students need to broaden their background with the study of language, culture, and other humanities fields, we also argue that the humanities major, if claiming to be liberally educated today, needs to broaden his/her background with exposure to the sciences and technology. All of the over six hundred language majors (in Chinese, Classics, French, German, Italian, and Spanish) at the University of Rhode Island, for example, are now strongly advised to develop a companion expertise with their language skills and cultural understanding, such as engineering, computer science, business, teacher education, journalism, or international policy studies. If students learn to speak other languages, that is good, but if they hope to contribute to society, they must consider how and where they might apply their language skills and what background they will need to do this. Furthermore, if a humanities major wishes to lay claim to being a liberally educated person in today's society, then he/she 
needs to have a firm understanding of the scientific issues and technologies which are the basis for the bulk of our daily routines, not to mention jobs. Language without application is inadequate, just as technology without language and culture, i.e., the liberal arts, is insufficient.

\section{Technology, Science and the Liberal Arts}

There is a message in these deliberations for both society as a whole as well as for higher education in specific. While we have always thought of educating philosophers or engineers, humanists or scientists, today we need to strive for philosophically astute engineers and scientists, and philosophers who understand, appreciate and can contribute to the world of science and technology. It is incumbent upon higher education, therefore, to rethink its structure and system of rewards for faculty in order to bring these traditionally disparate areas of the academy closer together and to provide all of their students the benefits of both a humanistic and professional education.

One can easily compare our current situation with the climate giving birth to the Morrill Act signed into law 150 years ago by Abraham Lincoln in 1862, through which the Land-Grant colleges and universities were created. As the wording of the bill attests, its authors were concerned about educating young people for the needs of the times, which were largely defined by the industrial revolution. They thus focused on the agricultural and mechanic arts, in contrast with the existing, traditional universities which were bastions of the liberal arts. It is critical to note, however, that in stressing professional education, they specifically noted that this should not be done at the expense of "other sciences or classical studies." Their goal was to "promote the liberal and practical education of the industrial classes in the several pursuits and professions in life." It is, therefore, very much in the spirit of the Morrill Act to suggest that we adapt our universities today to the needs of our technology driven contemporary society with a greater focus on the STEM disciplines, while at the same time recognizing and promoting the need for a background in the arts and humanities.

Is it a dream that higher education might reconfigure its offerings and redefine what it means to be a liberally educated person, or is it a necessity? Is it possible for engineering faculty (and others from scientific and professional fields) and philosophy professors (with others from the arts and humanities) to collaborate and provide their students with a more rounded education and thereby not only greater employability in today's complex global workplace, but also an increased sense of responsibility? Can higher education be so flexible? Can more be packed into an already full curriculum without adding time and expense to an already overpriced commodity? If so, how might this be achieved? What changes would be required in the structure and nature of American higher education? What forces would have to converge to make this possible? 
Needless to say, a change of this magnitude would, in an ideal world, call for an act of Congress comparable to the Morrill Act of 1862, resulting in a new kind of higher education institution for this age of globalization. In 2012, such a bill would not sponsor the land to create new campuses, but would rather sponsor and support a new vision of education designed to graduate technically and scientifically savvy young people with the breadth and depth required for careers in a complex global society. But, given the fact that we do not live in that ideal world at this time, it is perhaps more realistic that we in higher education look for ideas and inspirations and for individual initiatives which will point us in the right direction.

\section{Implications at the Departmental Level: Re-examining the role of Foreign Language Education}

Voices for change have been heard in the foreign language community in the United States for several decades now, even if without major change. In a 1994 ADFL Bulletin, Russell Berman called for a post-hermeneutic pedagogy which aims less for "native fluency" towards a feigned foreign identity, but instead for "foreign cultural literacy: the ability of the student to operate effectively in a different cultural setting" ". One model he mentioned in the context of teaching cultural literacy, one that promotes active skills rather than passive interpretation and provides the learner with the significance of engaging with foreign cultures is the model of Languages Across the Curriculum (FLAC). Four years later, this pedagogical shift resonated with the German Studies Association (GSA) in its new guidelines for curricular organization when it challenged the community to "reinforce cross-disciplinary initiatives in education," "foster new interdisciplinary models that encourage students to pursue in-depth knowledge while acquiring useful skills in several related fields and developing flexibility for their future careers", and to "relate curricula to the changing international environment."12 The GSA strongly encouraged extended stays and programs of study abroad to develop intercultural competency, deeper international understanding, and proficiency in a foreign language.

One more recent result of revisiting the status quo of foreign language education in this country in face of a language crisis ${ }^{13}$ was the 2007 report by the MLA

\footnotetext{
${ }^{11}$ Russell Berman, "Global Thinking, Local teaching: departments, Curricula, and Culture” ADFL Bulletin, Vol. 26, No. 1, Fall 1994, p. 10.

${ }^{12}$ New Guidelines for Curricular Organization at North American educational Institutions developed by the German Studies Association 1998 (GSA website)

${ }^{13}$ See Inside Higher Ed and Chronicle of Higher Education reports on the dire status of the humanities, and budget cuts threatening language departments across the country, e.g. Jaschik, Scott. "Das Ende for German at USC." Inside Higher Ed, April 11, 2008; "Left out of Gen. Ed." Inside Higher Ed April 19, 2010; Glenn David. "Traditional Language Programs have Declined Steadily Over Decades." The Chronicle of Higher Education, February 14, 2011; or McWhorter, John. "Which Languages Should Liberal Arts be About in 2010?" The New Republic, December 13, 2010
} 
(Modern Language Association) Ad Hoc Committee on Foreign Languages ${ }^{14}$ which offered background and context for the association's recommendations regarding the challenges and opportunities facing language study in higher education. Given the report's findings that only $6.1 \%$ of students declaring a foreign language as first major actually continue their studies towards a doctoral degree with the goal of becoming an academic while $94 \%$ of students are studying languages for another reason, the authors recommended a more broad-based approach to the foreign language major, as well as curricular reforms which make it more attractive and pragmatically more relevant for students whose primary interests may not include a foreign literature. This broader approach supported by alliances with other departments, e.g. by interdisciplinary course offerings, would have the additional effect of reinvigorating language departments as valuable academic units central to - and not on the margins of - the humanities and the university as a whole.

The cause of moving foreign language departments from the margins to the center of a university to avoid further marginalization is supported my MLA and ACTFL (American Council on the Teaching of Foreign Languages) survey statistics which - despite grim media reports on the subject - actually show that the number of language learners especially in K-12 has increased (for German ACTFL reports a gain of $8.21 \%$ from 2005 to $2008 \mathrm{~K}-12^{15}$, and MLA reports a gain of 2,2\% in 2009 over 2006) ${ }^{16}$. However, as Costabile-Heming analyzed in the Fall 2011 German Quarterly ${ }^{17}$, there seems to be a disconnect between the large pool of language learners in schools and the much smaller percentage, especially beyond the first year, in college courses, where the ratio between beginners and advanced courses is $4: 1$ (Furman, p. 27). Thus, language faculty need to do more on the postsecondary side of the equation to tap into this pool of eager learners and use marketing tactics to fill the pipeline of language courses, focus on translingual and transcultural competence, and offer attractive topics that are more relevant to the students' worlds. By giving the learning of a foreign language an additional purpose by linking languages with other disciplines, such as STEM, agriculture, business, textiles, or pharmacy, by tapping into the passion a student has for his/her first major and combine it with a second major which is relevant to the main academic interest, and by making this professional track even more potent by giving the dual majors an opportunity to apply their knowledge in a foreign

\footnotetext{
${ }^{14}$ MLA Ad Hoc Committee on Foreign Languages. "Foreign languages in Higher Education: New Structures for a Changed World.” New York: MLA 2007; accessed November 23, 2012 at http://www.mla.org/flreport

${ }^{15}$ American Council on the teaching of Foreign Languages. "Foreign Language Enrollments in K12 Public Schools: Are Students Prepared for a Global Society?” ACTFL 2010

${ }^{16}$ Furman, Nelly, Goldberg, David, Lusin, Natalia. "Enrollments in languages other Than English in United States Institutions of Higher Learning, Fall 2009,” MLA 2010.

${ }^{17}$ Carol Anne Costabile-Heming, "responding to the MLA Report: Re-Contextualizing the Study of German for the $21^{\text {st }}$ Century," The German Quarterly 84.4 (Fall 2011)
} 
country as well as a corporate or research environment through a long-term stay abroad, we have a powerful model in front of us, one which successfully moves language education from the margins to the center of strength of its respective university setting and one which empowers student learners to develop $21^{\text {st }}$ century skills to be applied in local and global communities, contexts, and cultures.

\section{Language and Engineering: A Template for Reform}

We, the authors of these pages, are both the current director and the recently retired founder, director, and developer of a now twenty-five year old program at the University of Rhode Island which has proven it possible for students to efficiently achieve the goals of a technical and a liberal arts education in a manner which is highly appropriate to today's workplace and financially responsible. The International Engineering Program (IEP), which was developed in close partnership with business and industry, is a cost-effective, career-oriented program combining the study of language and culture with engineering, and including a full-year of study and work abroad. It is a five-year undergraduate curriculum, leading simultaneously to both the BA in a language and the BS in one of the engineering disciplines. IEP grads are highly qualified engineers, who have stronger writing, speaking, analytical, and problem-solving skills, in combination with the command of a second language and the cross-cultural communication skills acquired through a year of in-depth study and work abroad. With over 400 graduates, the program continues to boast an almost $100 \%$ employment rate and demonstrate the fact that the humanities and the sciences can work together productively, i.e., that universities can indeed adapt to the contemporary needs of society. Our research documents the long-term value of such an education in today's workplace, where IEP graduates have been able to excel and achieve beyond their initial expectations, and make meaningful contributions to society. ${ }^{18}$

The IEP is built, of course, on the reality that engineering is a global field today and that engineers commonly work in teams crossing many cultural and linguistic borders. Even when not travelling, it is typical for engineers to be working on projects with others in widely dispersed locations, and such work requires knowledge of and sensitivity to other cultures and languages for communication to succeed. Engineers need to be many things today: technically savvy, analytically sharp, culturally astute, good problem solvers, able to take calculated risks, good communicators, cross-culturally informed, and lifelong learners. The IEP experience is designed to support the acquisition of all of these skills with its curriculum that combines the best of both a technical and humanistic education.

At the same time, the IEP model which has successfully linked the languages with engineering at the University of Rhode Island, and has additionally served as a model for a languages for the professions track within URI (for business, Computer Science, pharmacy, and textiles) as well as externally for various

\footnotetext{
${ }^{18}$ See: Grandin, John, Going the Extra Mile: University of Rhode Island Engineers in the Global Workplace, Rockland Press Rhode Island, 2011.
} 
successful international engineering or science programs such as at Valparaiso University, University of Connecticut, University of Cincinnati, Iowa State, Purdue, and more recently at Northern Arizona University, can claim that it gave language enrollment at URI a significant boost, and in the case of some, literally saved the languages at URI. The case of German at URI with a total of 135 majors shows that this development owes its enormous success to the IEP: currently $80 \%$ (and at times up to 90\%) of German majors are double majoring in engineering and German, $10 \%$ in Business \& German, and the rest is combining German with yet another discipline. Only a few students are "pure" German majors. It is easy to see that German would not have survived at URI without the "marriage" with engineering. Instead the German program, which does not even feature a master's or Ph.D. degree, became one of the largest in the country, the $2^{\text {nd }}$ largest in terms of major enrollment after the University of Michigan; and tying in $6^{\text {th }}$ place with the University of Madison Wisconsin with respect to graduating German majors. ${ }^{19}$ (The University of Rhode Island, of course, has less than 1/3 of the typical undergraduate enrollment of Big Ten schools.)

The following pages will be devoted to a detailed explanation and analysis of the University of Rhode Island's International Engineering Program and its relevance as a model for the reform of American higher education. Its current and past directors will explain how this unusual curriculum came about, and how this unique partnership between engineering and the humanities has served, in cooperation with business and industry, to educate truly rounded, employable young people, capable of representing the best of our society in a highly competitive, global milieu. It will be shown that higher education can benefit, perhaps even survive, by thinking and acting interdisciplinarily and form new and creative partnerships, both within and beyond the institution itself. After all, if engineering and language faculty can work together for the benefit of all parties, why cannot nursing and the liberal arts seek out productive collaborations, or pharmacy and language, or business and philosophy, or science and history, and so forth?

Perhaps most surprising is the fact that the five-year IEP is highly cost effective despite its extra year. It will be shown that careful institutional planning can, for example, result in a full-year study abroad program which is no more expensive than a year at the home campus. It will also be shown that an innovative and effective academic program can be developed in collaboration with cooperating corporate partners, with the latter assisting students with their financial challenges, thereby containing the cost.

Our discussion of the IEP model intends to show not only the need and value of a rounded humanistic and scientific education, but also a workable path for the reorganization of the current higher education structure which is so heavily burdened and constrained by historic traditions and interest groups. To merge disciplines such as language and engineering is not simple, and, even though

\footnotetext{
${ }^{19}$ According to statistics in Monatshefte, Vol. 102, Number 4, Winter 2010
} 
successful at URI, might seem to many to be basically undoable on a larger scale. Yet, the IEP experience at URI has proven such cooperation possible and to the benefit of all parties. We will explain that the program's success rests on the notion of partnership, with all parties committed to a common set of goals. The program began as an academic partnership, but, in turn, generated a series of other partnerships, both within and beyond the institution, which have inextricably linked the IEP to the public and private sector, thereby creating a sense of shared responsibility in educating future leaders. The program has unlocked a spirit of change, entrepreneurship, and excitement for each of the parties involved, enabling them to persist and overcome when barriers have emerged, and to be ever stronger, even after a quarter of a century.

\section{Partnering Across the Disciplines}

There are many kinds of partnerships, of both a personal and formal nature, often designating a business contract, but also reflecting a personal bond, such as marriage. All partnerships have a common goal or set of goals and are based upon the belief that working and being together will lead to something greater than working alone. Indeed, some ventures, which might involve marketing within a new environment, depend upon partner relationships for their very existence. For partnerships to be strong, there must be mutual benefit in the collaboration, without which failure is mostly just a matter of time. Counselors will tell us that partnerships are often fragile, sometimes for very good reasons, such as broken contracts, other times for reasons of human frailty, caused, for example, by greed, distrust, dishonesty, or the lack of simple give and take. Partnerships often carry risk, since they may unite parties in goals which might or might not be achievable. They must, therefore, often be built on hope and even depend upon a leap of faith.

The University of Rhode Island International Engineering Program (IEP) began as a partnership between two faculty, Dean Hermann Viets of the College of Engineering, and Professor of German John Grandin, who also served as associate dean of the College of Arts and Sciences. Both shared a common interest in Germany and the belief that all students, engineers included, would greatly benefit from becoming bilingual and by including a significant experience abroad as part of their undergraduate education. Recognizing that both of their respective areas would win from such a collaboration, and respecting and trusting each other, they soon recruited other language and engineering faculty for their discussion who jointly developed the concept leading to the IEP model. Students, they decided, could study language and engineering for five years, complete a six-month professional internship abroad during the fourth year, and earn both the BA in German and the BS in any one of the engineering disciplines. They would then enter the workplace with a significant advantage, especially given the increasing internationalization of the technical fields.

Grandin and Viets were well aware that they were entering a partnership fraught with barriers and hurdles. Aside from some outspoken engineers who saw no need 
for language study and a core group of language faculty who saw no reason to teach languages to engineers, there were manifold challenges from many bureaucratic corners of the academy. Would it be feasible or even wise to complete two undergraduate degrees in five years? Could we really arrange six-month professional internships in companies abroad? Who would teach the proposed special, content-based German classes for engineers? How would we recruit students to study both German and engineering? Would students see value in spending an additional year before entering the workforce? Who would find answers to these questions and complete these tasks? Despite the many questions, Viets and Grandin believed this all the challenges could be met and they agreed to pool their efforts and sell their idea, each to their respective faculty groups, arguing strongly that such a partnership would be mutually beneficial.

Indeed the partnership between Grandin and Viets, which grew to a partnership between engineering and languages, or viewed more broadly, a partnership between technology, science and the humanities, and subsequently a partnership between the university and the corporate sector, has been a great success and truly beneficial to all parties. The IEP today enrolls over 300 students, boasts over 400 graduates, and has expanded from the initial German and engineering model to include programs with French, Spanish, and Mandarin Chinese. It has benefitted languages, for example, by vastly increasing the number of German majors at the University of Rhode Island from a shrinking handful to over 135, the second largest enrollment of German majors in the country. Prior to the founding of the IEP, there had even been genuine concern for the viability of the German major. Benefits for the engineers included not only an increase in applicants to all engineering fields at URI, but also a substantial increase in the quality of the students. By marketing the IEP as a challenging program for gifted students who wanted more than what the pure engineering major could provide, the IEP became a magnet for such students. Gifted and motivated students committed to engineering, but seeking something to enhance and build on their technical skills, were attracted to URI and the IEP, often turning down admission offers from far more prestigious schools.

\section{The IEP as Community}

The IEP is by definition an academically challenging program. The engineering curriculum by itself has a reputation for rigor, whether at URI or elsewhere, with demanding admission standards and a high rate of attrition. To add a language major, additional humanities courses, and a full year abroad to that workload is an intimidating thought, meaning that the IEP is not for everyone; it is designed for those with considerable academic talent, the ability to grasp its benefits, the motivation to want to achieve its goals, and a willingness to work hard. For this reason, IEP students share a common identity from the beginning; they seek each other out and learn rapidly to rely on each other, to support each other and to work closely together. As a result, the program carries with it a certain esprit de corps

and sense of community, enabling students in the program, as well as faculty, to 
recognize each other as members of a special group within a large and far less personal state institution. IEP students identify themselves not just as mechanical engineering and German majors or electrical engineering and Chinese majors, but rather as IEP students per se. They believe strongly that they are doing the right thing by preparing themselves to work internationally and they bear the IEP label proudly and carry it with them, even as alumni, often participating in reunion events and returning to campus to encourage the younger generations.

To cite an example, Sharon Ruggieri, who is an alumna of the program with degrees in Spanish and Mechanical Engineering and a subsequent graduate degree from MIT's Sloan School of Management, gives clear expression to the special nature of being an IEP student and the value gained from the program's sense of community:

What differentiated the IEP from a typical engineering education at URI was the environment provided by the IEP students and the practical opportunities available. IEP students lived and studied together and we all recognized how much work we had; the students created an environment of mentorship and knowledge sharing where we helped each other understand class material.

When I joined the IEP Program I felt that I had finally found a group of people who I fit in with and an area of study that I was passionate about. Never before had I found a group of people like the IEP students; each student was a unique mix of creative and analytical with a bit of geekiness that we were proud of. To realize that there is an entire field and likeminded group of people that you can relate to is a great feeling and it propels you to success.

Building on the idea of IEP as community, the faculty leadership expended a great deal of effort to create a stronger physical presence for the program on campus, resulting ultimately in the establishment of a two-building complex at the main entrance to the URI campus now serving as the residential and administrative headquarters for the program. The IEP House and the Texas Instruments House provide program offices and meeting space as well as residential and dining facilities for 80 IEP students. Named for the chair of the IEP Advisory Board, the Heidi Kirk Duffy Center for International Engineering Education is a multifaceted meeting point for all IEP students and associated faculty. Students and faculty can gather there, take their meals there, and up to 80 students, including several exchange students from partner universities in Germany, France, Spain, Mexico, and China reside in the two buildings. URI students receive free tutoring from the native speakers in exchange for housing discounts for those students. Exchange students are paired with URI undergrads who are learning the language of their home country and are living with them on language specific floors (such as the German Max Kade floor or the Spanish floor). This miniature partnership between U.S. and foreign student provides a relaxed and less stressful atmosphere to test a 
student's budding linguistic skills before heading out to the target country. Research on language learning in university language houses has shown that the gains in living in such housing can surpass those acquired in short-term study abroad stays and clearly outpace the progress of students learning only in the classroom. ${ }^{20}$ The Center is truly a living and learning community, where all IEP students feel at home, seek advice and counsel, receive tutoring assistance, participate in study groups, and practice their language skills.

The IEP House and TI House were made possible by a partnership between the IEP faculty, the university, and private citizen and corporate donors. The idea arose as the result of the deterioration of the university fraternity system, which left the URI campus with these two vacant fraternity houses, both in very poor condition and badly in need of extensive renovation. Had the IEP not seen the potential of restoring these two structures as a home for the program, they most certainly would have remained vacant until the university secured the funds to raze them. The IEP, however, decided that the buildings could be saved and made a bid to do so, with the intent of operating them independently, if not as profit centers, at least as a complex which could take in enough income from student residents to enable them to be self supporting. Though the two buildings are now University of Rhode Island property, they were owned at that time by the fraternities. This made it possible for the IEP to negotiate directly with those organizations and with private contractors to make the necessary renovations. Complex state bidding processes were largely obviated, enabling the program to move forward on the project more rapidly than the university might have been able to do on its own.

The two-building Center was made possible by a self-financing structure based upon income from student residents and special summer programs which has proven itself viable and effective and is still in place today. It would not have been possible, however, without the substantial support of private and corporate donors who strongly endorse the IEP, its goals and its success. Over \$1.5 million dollars was raised from companies and individuals, including Heidi Kirk Duffy, the Texas Instruments Corporation, Sensata Technologies, ZF Friedrichshafen AG, the TRW Corporation, and the Max Kade Foundation. The University of Rhode Island also took over individual parts of the project and has more recently assumed a large part of the debt for the final purchase of the IEP House.

It is important to note that the IEP living and learning community is a wholly entrepreneurial outgrowth of the program and that it is self-managed with very little infrastructural support from the university. The full-time IEP housing coordinator is paid from the income collected from students and special programs, as is the full-time kitchen staff, who serve meals three times a day for residents and other IEP students purchasing meals on a per meal basis. The cleaning staff is likewise on the IEP payroll, just as several ongoing maintenance items. Jokingly,

\footnotetext{
${ }^{20}$ Rob A. Martinsen, Wendy Baker, Jennifer Bown, Cary Johnson, "The Benefits of Living in Foreign Language Housing: The Effect of Language Use and Second-Language Type on Oral Proficiency Gains," The Modern Language Journal, 95, ii, (2011)
} 
we have often argued that the IEP is in the hotel and restaurant business, while in all seriousness we point proudly to the fact that these services are offered to IEP students at less than the costs of similar services in the URI dormitories.

Have there been any regrets about the creation of an IEP living and learning community? While we did have anxieties in the beginning about creating residential space for undergraduates in the buildings where we have our faculty offices, the experience rapidly turned out to be extremely positive. We, the current and past directors of the program, greatly value being able to see our students on a daily basis, being able to eat lunch with them, sit down for a cup of coffee, and know that they can find us when there is a desire or need. And we take pride in the fact that there are no dormitory "police" in the complex. The students govern themselves by means of an elected house council, resulting in very few incidents of bad behavior in the program's fourteen-year history. IEP students are proud to be IEP students and they understand that this honor carries a certain level of responsibility.

To gain the student perspective on living in such a complex, we asked one of our former students to comment. Sheida Danesh is an IEP alumna currently working on her Ph.D. at MIT, who lived in the IEP House for $21 / 2$ of her undergraduate years. Her words summarize what we have heard from so many:

I LOVED living at the IEP house. Really, it's probably the part of college (other than my year abroad) that I feel most nostalgic about. Other than its obvious convenience to classes, I made all of my closest friends from college there. The house was both very social and very studious at the same time. Most of my friends there were friends I had first made through classes. It's very easy to get close to people when you are taking (and struggling through) the same classes together and also living in the same house. It made school work much less stressful because we all helped each other out; if I didn't understand a concept we learned in class, or needed to know for an exam, it was so much easier to go across the hallway at $10 \mathrm{pm}$ to one of my friends' rooms instead of trying to learn by reading a text book. Living in the IEP house was really the best of both worlds. I mean, really, who wouldn't want to live in a house full of their best friends without having to worry about their living habits?!

\section{A New Kind of Teaching}

Establishing the International Engineering Program meant a major shift in professional duties for founder John Grandin. Prior to that time, he had been a traditional professor of German, teaching three courses of German language and literature per semester and pursuing a research and publication program in German literature. But after launching the IEP together with Hermann Viets, his career took a very different direction. He first became a grant writer and fund-raiser, then a program developer, student recruiter and advisor, and teacher of specialized German language courses for students of engineering. The next steps involved the 
creation of an advisory board from the public and private sectors, and outreach to companies, both in the U.S. and Germany, to foster interest in the program and its students and to create six-month internship opportunities in Germany. Soon there was the addition of a program in French, to be followed by Spanish and Chinese. Then came the housing program, the dining program, and renovation of the buildings, with all of the issues associated with their management and maintenance. As the program grew, the duties and responsibilities grew even more. Soon there would be the addition of an assistant director, the development of short-term study tours for younger students, the creation of a regular newsletter, outreach to alumni, complex recruiting programs, and meetings with alumni, not to mention the founding of a yearly professional conference, the Annual Colloquium on International Engineering Education.

It is safe to say that an IEP director, though he or she may bear the title of professor of German, is anything but a typical university professor. The job migrated for Grandin from nine hours a week in the classroom to a 24/7 position of management and coordination, all of which he has always considered, nevertheless, to be variations on teaching. He came to see himself as a manager, entrepreneur, and innovator, whose activities are committed 100\% to developing academic and career opportunities for students, and helping the university to align itself with society's needs.

Though Grandin did less and less traditional classroom teaching as the program matured, he came to see himself as a new kind of teacher with increasing hours of contact with his students. An open-door office brings in a steady stream of students; preparing students for study abroad and professional internships is technically not a classroom experience, yet an important part of the educational goals of the IEP, requiring many meetings, face-to-face and in groups; helping students design their foreign language resumé or draft their letters of application for internships is an equally important educational step; sitting down with students at the lunch table to learn how they are doing and what problems they may be having is likewise an important part of this new form of teaching.

This new phase of his professional career did not mean that Grandin would turn his back on the research and publication side of his professorial obligations. It did mean, however, that he would give up his earlier role as a researcher on the works of Franz Kafka, to become a writer, presenter, and disseminator based on his experiences as an international educator and academic entrepreneur. Indeed, Grandin's resumé grew steadily during the IEP years, as he became more and more of an authority on the internationalization of engineering education, the placement of students in international internships, fund-raising and grant writing, and the teaching of content based language courses, all of which are reflected in his lengthy list of publications.

The unique shape of Grandin's career and the many sides of the program worked well for several years, but gradually entered a crisis phase as it became time to 
think about retirement. How, we asked, would one find someone else to pick up all these pieces and continue the program? There is no graduate program training future professors to be IEP directors! There is no systematic provision for tenure and promotion of such a faculty member. Would there be another German professor who could oversee such a program, advise students, raise funds, coordinate outreach to global companies, manage a staff, and continue to build the bridge between engineering and the humanities? Would there be an engineering faculty member who could take this over?

Fortunately the questions were answered positively as the program searched nationally and internationally and found Dr. Sigrid Berka, coauthor of this paper. She too began her career as a faculty member in German at Barnard College, with a Ph.D. in German literature. After teaching for several years, she had found her way to an administrative position at MIT, where she was likewise managing the placement of engineering students for internships with companies and research laboratories in Germany, and served as industry liaison and fundraiser for the MITGermany Program which is part of the MIT International Science \& Technology Initiatives (MISTI). As a natural teacher, an excellent writer, a well-organized administrator and creative and innovative thinker, she has been able to jump in where Grandin left off upon his retirement in June 2010, and the program continues to thrive. She too knows this position to consist of a new kind of teaching and advising, which can be far more demanding than the traditional role of a professor of German, but, at the same time, far more exciting. What this means for the University of Rhode Island in specific and higher education in general will be discussed below.

\section{A New Kind of Learning}

The IEP curriculum is far more comprehensive than that of the traditional major, whether in engineering or the humanities. Though it has its share of typical classroom learning, the overall program is part of a well-planned all-encompassing living, learning, and working experience focusing on the development of technical understanding and skills, as well as in-depth language and culture study and learning. What happens in the classroom is supported outside the classroom through a regular interaction with peers and faculty, through study tours abroad, through professional internships at home, through study and work abroad, and through capstone learning experiences in the final year. In short, the IEP provides a supportive framework enabling motivated and gifted young people to prepare broadly and extensively for lives and careers in today's complex global society. The IEP curriculum thus reflects the goals a strong language program should have according to ACTFL: to develop students' language proficiency around modes of communicative competence reflecting real life communication. Unlike the classroom of yesteryear that required students to know a great deal of information about the language but did not have an expectation of language use, today's classroom is about teaching languages so that students use them to communicate 
with native speakers of the language. This is what prepares them to use their language learning as a 21 st Century Skill. ${ }^{21}$

ACTFL's national standards are undergirded by five goals, the five " $C$ "s, and each one of them is met by the goals and the practice of the IEP curriculum: IEP students "Communicate" in languages other than English; they gain knowledge and understanding of other "Cultures"; they "Connect" with other disciplines and acquire information; they develop insight into the nature of language and culture by "Comparing" the foreign with their own; and they participate in multilingual "Communities" at home and around the world.

Both the language and the technical learning experiences are integrated into each semester of the five-year program. The language learning is further highlighted by the design of content-based language courses, allowing the students to enhance their language skills in courses infused with technical materials. ${ }^{22}$ IEP language learning also focuses on cultural issues and cross-cultural communication, helping to prepare students for their year abroad as exchange students and professional interns. In the final year, after students have strengthened their language abilities with a year of in-country use, students are prepared to deal with sophisticated texts selected from the history of the culture and literature of their chosen language. By graduation they have advanced-level proficiency in the language, backed by direct experience with engineering as it is taught at a technical university and as it is practiced in the country of their choice. Students in study abroad situations tend to interact and speak more and use language as a tool more than an end goal if they are engaged in a pragmatic, natural environment where problem solving in a team is required; where they can go beyond simplistic and superficial language use; where their interaction fulfills a real-world purpose (e.g. solving a technical or medical problem with others) in a context they are passionate about. ${ }^{23}$ We can only verify this claim from experience showing that the linguistic gains are highest for our students after the six month internship, which is also the time when they separate from their peer cohort at the partner university, and are sent in all directions to their internship hosts. They come back with at times amazing command of advanced technical concepts.

\footnotetext{
${ }^{21}$ The $21^{\text {st }}$ Skills Map. Designed in Cooperation with the Nation's World Language Educators, spear-headed by ACTFL and the Partnership for $21^{\text {st }}$ Century Skills (P21), accessed on Nov. 24, 2012 at http://www.p21.org/storage/documents/Skills\%20Map/p21_worldlanguagesmap.pdf

${ }^{22}$ See: "German for Science and Technology: Teaching Strategies for Beginning Students." Die Unterrichtspraxis / Teaching German 34.2 (Fall 2001): 119-132 and Rarick, Damon O., "The Student Centered Classroom Made Real: Transforming Student Presentations in an Advanced Course on Technical German,” Die Unterrichtspraxis/Teaching German 43.1 (2010), pp. 61-69.

${ }^{23}$ These observations have also been attested to by researchers at Brigham Young University when observing language learners in service learning projects abroad. See: Martinsen, Baker, Dewey, Bown, and Johnson, "Exploring Diverse Settings for Language Acquisition and Use: Comparing Study Abroad, Service Learning Abroad, and Foreign Language Housing," in Applied Language Learning 2010, Vol. 20, Nos. 1 \& 2, pp. 45-69.
} 
The IEP is a demanding program in terms of its language and time-spent- abroad requirements. Students in the program may participate in optional, short-term study tours abroad without considerable background in the language. However, no student is sent abroad for study and professional internships without having completed at least six full semesters of language study or the equivalent, and at least six semesters of the engineering curriculum. With this stringent requirement, the IEP sets itself apart from most study abroad programs, whether in engineering or any field. The trend today in American higher education is to send more students abroad, but predominantly for short-term stays such as in the summer or between semesters, and for programs conducted solely in English. ${ }^{24}$ IEP students complete a full semester at a partner university, where they study engineering and language/culture, and complete research projects in university institutes, with all work done in the language. The work is pre-approved, enabling students to complete a full semester of credit, which is transferred to URI.

The internship follows the semester of study and is carried out in collaboration with cooperating companies in the country of the target language and culture. Internships are professional, full-time, paid, and conducted under the supervision of an engineering mentor. The internships are also arranged to coordinate with students' majors, i.e., mechanical engineers often work with automotive-related companies, electrical engineers with companies such as Siemens, chemical engineers with companies such as BASF, and so forth. While on location during the six-month period, the students are required to submit monthly written reports in the foreign language, discussing their work and offering observations on the culture, both in a day-to-day sense, but also as it impacts engineering practice in that location.

By working carefully with our partner companies, the IEP strives to coordinate the overall IEP learning experience with the growth of the students' professional skills on a step-by-step basis. IEP students have the opportunity to work first as summer interns in the U.S. with many of our partner companies, thereby gaining the first exposure to professional practice in a global company close to home. Ideally this first internship becomes the first practice-oriented building block for a comprehensive plan, leading to related research at a partner university abroad and a related project for the professional internship in that country. Finally, this same topic or subject matter can form the basis for the student's final year capstone research project at URI, again conducted in concert with the same partner company.

To cite an example, 2010 graduate Sheida Danesh chose German and electrical engineering as her fields of study. Following her sophomore year, she joined Hexagon Metrology in North Kingstown, Rhode Island as a summer intern, working on projects related to coordinate measuring devices. Based on the success of that summer, she was invited to return to Hexagon for a second summer, shortly before going to Germany for her fourth academic year. With help from the IEP

\footnotetext{
${ }^{24}$ See: Institute for International Education, Open Doors 2012 Report
} 
leadership, Sheida was able to conduct further research on coordinate measuring devices at the well-equipped Institute for Metrology at the Technical University of Braunschweig, while there for her exchange semester. The next logical step was for Sheida to follow her Braunschweig semester with a six-month internship at the German division of Hexagon Metrology in Wetzlar. It was then obvious to all that Sheida would collaborate with Hexagon for her senior capstone project in her final year at URI. At the conclusion of her IEP education, Sheida, with her extensive experience with coordinate measuring systems, and Hexagon were a perfect match for each other and she was sorely tempted when receiving an offer. However, the IEP, and especially the year abroad, boosted Sheida's self-image and selfconfidence to the extent that she decided to go on to graduate study rather than begin work right away. Daring to shoot for the top, Sheida applied for admission to MIT where she is now a doctoral candidate.

It is important to point out that Sheida's work with Hexagon meant not only a well-coordinated and comprehensive technical and cultural learning experience, but also a financially manageable education. Sheida was well-paid as a full-time summer intern at Hexagon and was able to work as well part-time at the company during the academic year. While at Hexagon in Germany, she likewise received a stipend enabling her to cover all living expenses there. And when she left Hexagon in Germany, the company gave her a generous bonus as a sign of their extreme satisfaction with her work. Though Sheida by no means received a free education, if one couples these financial sources with the other scholarships she received from URI and from IEP endowed scholarship funds, she did very well. Sheida financed her own undergraduate education without calling on support from her family.

The IEP year abroad, such as that experienced by Sheida, is financially very cost effective, especially when compared with most study abroad programs arranged by American universities. The IEP semester of study is based upon a one-to-one exchange relationship with the IEP partner schools. Participants in the exchange meet all financial obligations at the home institution and then exchange places, one-for-one. By special arrangement, IEP students pay in-state tuition for the one semester of study, whether they are in-state students or not, and they are not required to pay any tuition during the internship semester. Sheida thus paid URI tuition for one semester of study, for the entire year. Living expenses came out of her own pocket while in Braunschweig, but the latter are highly subsidized at German universities and thus far less expensive than in Rhode Island. While at Hexagon, she received a stipend to cover her living expenses and she had her main meal of the day in the company cafeteria. All in all, and despite the additional year of study, Sheida was able to leave URI with very little debt, and the overall program and record of accomplishments made her very attractive to MIT, where her graduate studies are fully financed by an assistantship. Had she wanted to enter the workforce rather than continue her studies, that would have been easily accomplished. 
When asked to provide input about her IEP experience, Sheida also pointed out an aspect of the program common to many other IEP students. Above and beyond the purely academic and professional gains, Sheida bonded with many fellow IEPers, thereby establishing life-long friendships. Beyond that, she also fell in fell in love with an IEP classmate, with whom she has been together since graduation. There are of course many reasons for falling in love, but we have noted in the IEP that a shared academic curriculum and especially the shared experience of study and work abroad contribute strongly to a core of commonality which means an even stronger personal bond. We are proud of the number of IEP relationships and IEP marriages!

\section{Expanded Learning Outcomes}

In a recently published study of fifteen IEP graduates in the workplace, ${ }^{25}$ John Grandin sought to define more clearly what skills or qualities IEP students specifically gain from the international components of this unique five-year program, and how these come into play in their professional careers. What skills are gained from the IEP curriculum and from the time spent abroad? What skills or qualities are acquired over and above those of a traditional engineering program? And what difference have the outcomes of the IEP education made for them in their lives and careers since graduation? Grandin interviewed the fifteen students in depth, asking them to look back at their undergraduate years and to evaluate what they achieved as a result of the IEP, and how it may have helped them in their professional lives.

Historically the IEP has always promoted itself as a special program with a strong international dimension. It promises a first rate engineering education, and language skills strong enough to participate in an accredited semester-long study abroad program at a partner university, as well as a six-month professional internship. The IEP has always argued that study and work abroad in the language give access to a culture and professional practice in a manner otherwise not available. Students develop strong language skills, strong cross-cultural communication skills, appreciation for different points of view and different attitudes influencing things like design, safety, environmental protection, and quality. IEP students also become mobile, flexible, and tolerant of difference.

Grandin was able to legitimatize these claims through the case studies of these fifteen alumni, but he was also able to discover other commonalities among this group that the program had not typically identified. Each member of this group stressed, for example, that he or she had developed far more advanced problem solving skills during the time spent abroad. They pointed out that they were sent to another culture well outside of their comfort zone, where all matters, both large and small, were dealt with in another language, and where they were expected to take far greater responsibility for themselves. Adapting to a different university

\footnotetext{
${ }^{25}$ Grandin, John, Going the Extra Mile; University of Rhode Island Engineers in the Global Workplace, Rockland Press Rhode Island, 2011.
} 
system, a different dormitory philosophy, a different banking system, different diet, different sense of humor, different interpersonal reaction patterns, and so forth, required attentiveness and a sharp learning curve, all to be dealt with in a milieu which provides far less hand-holding and spoon-feeding than the American university system. Learning to use their language skills and to build on the background that had been provided through three years of study was a huge challenge in and of itself. But beyond that, they all reported that each day brought new issues, new problems, new challenges, linguistic, cultural and otherwise, but that this process in turn resulted in major personal growth during the year abroad, enabling them to return home and enter their careers with a far greater maturity than most of their peers who did not have such an experience during their undergraduate years.

The members of this group also reported that their success in learning to communicate in another language and in an another culture, along with their new problem solving skills led to a greater sense of self-confidence, and a new sense of what they might be able to achieve in life. Learning at age 21 that one can live abroad, that one can communicate in another language, that one can, for example, successfully take a seminar in Finite Element Analysis in German and apply that knowledge in the workplace, builds confidence and helps one to understand that goals once thought to be mere dreams are now achievable.

While studying and working abroad for one year provided a boost in selfconfidence and helped to raise the personal bar for this group, the fifteen alumni also reported that the experience enhanced their ability to take calculated risks. In looking back, the alums could view the IEP curriculum itself as a risk which paid off handsomely. They committed to learning a new language, spending a year abroad, taking engineering courses in a foreign language, going to work for a company with unknown supervisors, no prior experience, unclear assignments in advance, and yet they met all these challenges and succeeded. As a result, they were each able to reassess the future and the goals they might set for themselves. Matthew Zimmerman, for example, had the courage to turn down job offers in his senior year, with the belief that he could start his own company - which he did. Sharon Ruggieri turned down an offer from a major automobile manufacturer with the hope that she would be accepted to MIT's Sloan School of Management which she was. Rather than go directly into a full-time job in the U.S. after graduation, Daniel Fischer chose to do a second internship with Siemens in Germany, with the hope that he might be able to land a regular position with them at their German headquarters for MRI technology - which he did. Sareh Rajee decided to apply for early admission to Brown Medical School - where she recently completed her MD while also earning the Masters in Public Health from Harvard. In their own words:

The IEP experience, especially my year abroad, helped me build confidence in my interpersonal communication skills, in my independence, and in myself as an individual. The IEP showed me what I am capable of, and I am now 
a stronger, happier, and more independent person because of it. Sareh Rajaee, 2006, Biomedical Engineering and German

The IEP put me in situations that I would not have experienced in the U.S. In that sense, you grow and learn how big your comfort zone is and what you can do when you find yourself in situations on the border of or outside of this zone. Daniel Fischer, 2002, Electrical Engineering and German

I'm a much different person as a result of the IEP. The world is a lot smaller and my ambitions are a lot larger. Challenges don't look as daunting, and as a result, I'm more willing to provide my opinion or step forward to work on a project. Johnathan DiMuro, 2003, Chemical Engineering and German

\section{Partnering with the Private Sector}

As explained above, the IEP is built upon a series of partnerships, beginning in 1987 with the initial shared vision of Dean of Engineering Hermann Viets and German Professor John Grandin. The resulting partnership between engineering and languages faculty has grown significantly and thrived over the years, with the two fields working closely together in many ways. Going far beyond the superficial or symbolic level, the staff and faculty involved in the program today feel an equal allegiance to the two colleges involved, and vice versa, even with the IEP Director, for example, having voting rights on the Engineering Dean's Council. The College of Engineering and the College of Arts and Sciences are equally proud of the program, have joined in helping to support its costs, and both have made a major commitment to seek extramural funding for its long-term infrastructure.

Faculty from each area have discovered the many benefits of their IEP partnership. The program has helped to recruit a larger and stronger student body; it has made it possible to launch joint research projects with faculty from partner institutions abroad; and it has made the faculty more competitive for research funds from agencies such as the National Science Foundation. There are joint faculty publications, and joint presentations at both technical and language based professional meetings. In the final analysis, the IEP has brought considerable recognition to both engineering and language programs at URI from peers at other institutions and leaders in higher education, and many awards have come to the program from both the engineering and the languages professional communities.

If the IEP relies on a willing interdisciplinary partnership within the institution, its relationship with the private sector is equally important and equally vibrant. Since its beginning, the IEP has relied on globally involved companies who see the value of the program and participate by providing paid internships to qualifying students. Initial contacts with companies in Germany were made by Hermann Viets and John Grandin, with the promise that we would send students with a good conversational ability in the language and at least third-year standing in the 
engineering curriculum. The companies, in turn, agreed to provide a meaningful, supervised, professional internship experience with a housing arrangement and a subsistence stipend. From the beginning it was clear that the companies valued the idea of American engineers with global communication skills and most hoped, in the long run, to be able to hire IEP graduates.

Viets and Grandin found business and industry very open to the idea of a partnership with the IEP and more than willing, if not eager, to play a role in shaping such an educational curriculum. Our corporate partners thus helped us found an external advisory board for the program, whose members would help guide its direction and eventually also support it financially. The IEP Advisory Board is made up of members of both the public and private sectors, including the German Consul General in Boston and corporate leaders from several global companies, some of which are U.S. companies with subsidiaries abroad while others are European companies with strong representation in the U.S. The Board is chaired by a private citizen, Heidi Kirk Duffy, who has a strong commitment to the IEP and has been one of its strongest financial supporters. It meets as a group annually, most often at the URI campus, but every third year or so at a location abroad, at one of our partner universities or at the headquarters of one of our global partner companies. To date the group has met in San Sebastian, Spain, in Paris, and in Munich, Berlin, Friedrichshafen, and Braunschweig, Germany.

Our corporate partners all provide internships for our students, with approximately 50 placements per year in Germany, France, Spain, Mexico, and China. Given the fact that participating companies are global in their structure and commitments, it is often possible to work with the same companies in multiple countries. Our German partner, ZF Friedrichshafen AG, for example, has provided internships for IEP students in Germany, France, Spain, Mexico, Brazil, China, and the U.S. Ideally, as in the case of Sheida Danesh described above, students are placed with a partnering company for a summer position following the second and/or third years of the curriculum, and then placed with the same company when completing the six-month position abroad, e.g. with Hasbro Corporation in Pawtucket, RI, then Hasbro in Shenzen, China; with Sensata Technologies in Attleboro, MA, then with Sensata in Guangzhou, or with Toray Plastics in Quonset, RI, then with Toray in France. This provides a consistent educational plan for the student, while giving the company the opportunity to review the student's work and capabilities in two different locations. The student also, in such situations, collaborates with the same company when completing the required senior design project.

Most of the IEP cooperating companies have become willing partners, partly out of their personal eagerness to be involved in education innovation at the university level, but also due to the direct benefit they can accrue by hiring IEP graduates. Our partner companies are very aware of the need for engineers with international experience and global communication skills, and are thus eager to be in the front line when the best students are ready to enter the workplace. Now that the program can boast an alumni body of over 400, the partner companies can assess 
the extent to which their participation has been worthwhile. Although many of the grads have gone to work for other firms, a sizeable number has indeed joined the cooperating companies. Thus, there are IEP graduates working for Siemens in Germany and the U.S; for BMW and Mercedes, likewise in Germany and the U.S; for ZF Friedrichshafen AG in Germany, the U.S., and Japan; for Continental AG in Germany; for MTU Aero Engines in Germany and the U.S.; for Sensata Technologies in the U. S.; for Hexagon Metrology in the U.S.; for the Deutsche Bahn in Germany, for Total in Paris and so forth.

Partner companies see it in their direct interest to work with the IEP and also to support the IEP financially over and above the promise of internship positions and stipends. As noted above, several of our companies supported the development of the IEP House and the Texas Instruments House. In addition, many of our partners have provided scholarship support for our students, in the form of direct grants or endowed scholarship funds. More recently, our partners, along with many alumni and other friends of the IEP, have contributed to an endowed directorship fund, which is being established in the name of emeritus director John Grandin.

\section{Other Partners from the Private Sector}

The IEP has also benefitted from the support of both private citizens and private foundations who have responded enthusiastically to the goals of the IEP and the concept of preparing American engineers to compete successfully in today's global workplace. IEP Advisory Board Chair Heidi Kirk Duffy has been a faithful and committed supporter of the program since its founding and has served as its board chair for over twenty years. A German by birth, she was able to help the IEP make some of its original connections with companies in Germany, such as the automotive giant ZF Friedrichshafen AG. Out of gratitude for her ongoing support and years of help, the two-building IEP living and learning community has been named for her as the Heidi Kirk Duffy Center for International Engineering Education.

The IEP has also been supported by private foundations which have identified with the goals of the program. The Max Kade Foundation, for example, was happy to support a program which creates a new and powerful rationale for the teaching of German language and culture in the U.S. Kade supports several IEP program functions annually and was a major donor for the creation of a German language floor in the Texas Instruments House. In addition, the Max Kade Foundation supports students enrolled in the dual masters program between URI and the Technische University Braunschweig, and it has, for the first time this year, supported a Distinguished Max Kade Lecturer to teach at URI in Spring 2013. The Van Meeteren Foundation in Germany has been eager to provide financial assistance to the IEP as a new and innovative model for the exchange of engineering students between the United States and Germany. Van Meeteren provides funding to support the travel and living costs for students going for their year in Germany. Another avenue of private support is the endowment formed in 
the name of a former faculty member at URI who wished to help Rhode Island students learn languages other than English. The Demers Scholarships have gone to several IEP students in recent years, especially to those IEP students going to China for a year of study and internship.

\section{Partnerships with Government}

The IEP has relied heavily on financial support in the form of governmental grants from the United States, the Federal Republic of Germany, and the Peoples Republic of China. The very first extramural support for the program came from the Fund for the Improvement of Post Secondary Education (FIPSE) in the U.S. Department of Education. FIPSE leadership at that time was enthusiastic about sending engineering students abroad and rethinking how and for what reasons languages are taught in American colleges and universities. As a result, the IEP worked closely with FIPSE for eleven consecutive years, each of which included financial help for the development of different phases of the program. FIPSE supported the launching of the initial German and engineering Program; it supported the creation of its exchange program with the Technical University of Braunschweig in Germany, including its dual degree masters program; it supported the creation of the Spanish IEP model; and it supported the design and introduction of specialized, content-based language classes for students of engineering.

In more recent years, the IEP has been supported by the National Science Foundation, as URI faculty expanded the program's emphasis beyond the purely educational level to include multinational research projects. The NSF Program in International Research and Education (PIRE) was designed to impact scholarly research, but also the preparation of graduate students and young scholars, who, in the eyes of NSF, will no longer be able to compete without learning to work globally. In this spirit, several IEP faculty were able to pull an international team together, including partners from Germany, to develop new techniques for lab on chip technology. The project was to be both a scientific and educational effort, insofar as it was conducted by a cross-national team, with contributions from both sides. NSF supported this project for over six years with a $\$ 2.5$ million grant.

More recently the IEP and URI have been recipients of over \$1 million of support from the Department of Defense's National Security Education Program. By way of NSEP, URI has become a Chinese Flagship institution, meaning that it has pledged to develop a Mandarin Chinese program dedicated to language learning at the highest level. Chinese Flagship students must participate in intensive courses throughout their undergraduate years and spend an entire year studying and interning in China, leading to an almost native proficiency level of the language.

The IEP has also been generously supported by the German government with grants from the Economics Ministry and the German Academic Exchange Service. Both agencies have favored the IEP as a unique and replicable model for encouraging young American professionals to speak German, to feel at home in 
the German culture, and to be able to support the economic and business interplay between the two countries. Germany has been a willing partner with the IEP, as the program has been viewed as a new and effective paradigm for stimulating interest in Germany.

The Economics Ministry's Program for Transatlantic Encounters has supported the IEP twice with sizeable three-year grants that enabled the program to expand, support its students abroad and develop a dual degree masters program with its partner university in Germany, the Technical University of Braunschweig. The latter has been very successful and, as the first of its kind, has pointed the way for many other German-American university partnerships.

The German Academic Exchange Service (DAAD) has also been very supportive of the IEP. For several years it has contributed to the annual German Study Tour for younger IEP students, enabling them to get a first glimpse of Germany and the IEP partners in both education and business/industry. It has also provided outright grants to support the program, subsidies for the Annual Colloquium on International Engineering Education, and scholarships for some of the strongest students going abroad each year. In addition, the DAAD provides matching funds for a DAAD lecturer in the field of German as a Second Language (DAF) who is a welcome and needed addition to the faculty in URI's German section, and is being renewed every five years.

When the IEP decided to develop a program in Chinese, it also found a ready partner in the Chinese government. Representatives from the Chinese Consulate in New York were highly impressed with the idea of combining Chinese language learning with the study of engineering, and thus readily agreed to help create a credible Chinese language program at URI. The first step was support from China for a full-time faculty member in Chinese for three years, with the understanding that URI would then support the position from that point on. The Chinese also selected URI as a site for a Confucius Institute, to support the Chinese language program at URI and to provide information to the community about Chinese culture.

\section{Partnerships with Universities Abroad}

Because of the requirement that IEP students spend a semester of study abroad prior to the six-month professional internship, the program has developed close working relationships with universities in Germany, Spain, France, Mexico, Canada, and China. These university partnerships are reciprocal, meaning that students are exchanged in both directions on a one-to-one basis. Students take care of financial obligations at the home institution and then simply exchange places for that period of time. By mutual agreement, the partner institutions provide for the needs of the guest students, often designing courses for the specific needs of the students, and arranging specific research opportunities. IEP students at the Technical University of Braunschweig in Germany, for example, take language 
and culture courses along with at least one pure engineering course and a research project in one of the schools many research institutes. All work is conducted in the language of the host institution. ${ }^{26}$

The relationships with these partners abroad have matured over the years, as demonstrated by the introduction of dual degree graduate programs, and the exchange of faculty for both teaching and research purposes. Students and faculty, therefore, have benefitted by the transfer of knowledge and exposure to engineering as practiced in the academic setting of other nations. Taking classes in a different setting and in a foreign language is a powerful path for students to acquire the skills implicit in the study of both the hard sciences and the humanities. The time spent abroad adds significant value to the education they receive at their home institution.

While there were initial fears about sending our engineering students to schools abroad, all of these evaporated once faculty had a chance to make mutual visits to the campuses of our partners. Each recognized the strengths of the others and found that they each shared the same concerns and goals for their students. At the same time, they recognized differences, most of which were found to be complementary to the strengths at home. Both faculty and students learned that they could benefit through interaction with peers abroad.

\section{What are the Barriers to such Reform?}

If we have successfully presented the International Engineering Program as a model to provide today's students with the extensive knowledge and skill sets required for the contemporary workplace, then we need to ask what stands in the path of its adaptation on a broad scale. As acknowledged above, the marriage of engineering with languages is unique and few have tried to imitate the IEP, despite its obvious advantages and despite its many admirers. Why is this the case?

The problems begin with long-standing traditions in academia, as well as the innate desire to preserve the status quo. As mentioned above, language faculty view themselves as humanists, with their disciplines based in the study and teaching of national literatures. Furthermore, many language faculty fear the notion that their language courses might be placed in the "service" of other disciplines. On the engineering side, there are many who argue the superiority of English on the global scene and see no value in devoting time to learning languages other than English. Additional time, they argue, should be devoted to supplemental technical courses. These barriers can only be overcome if, as was the case at URI, the doubters begin to see the value of working together with faculty across the disciplines, leading to the understanding that both parties benefit through such a collaboration. As a result of the IEP, both the language and

\footnotetext{
${ }^{26}$ Christina Neidert, "Sheltered Program at the Technische Universität Braunschweig, Germany. Facilitating Studying and Working Abroad: Best Practices," Online Journal for Global Engineering Education, Vol. 6, Issue 1, Article 3, December 2011.
} 
engineering classes were soon full of very talented students, many of whom would not have attended URI if there were no such unique program.

Another major hurdle for the development of such innovative curricula is found in the nature of the faculty tenure and promotion system, which, by design, directly discourages faculty from committing time and effort to programs like the IEP. Language faculty are promoted as a result of good teaching, but not without publication records in their respective literature or language acquisition specializations. Engineers, of course, will not be tenured or promoted without a strong research record and success at attracting substantial outside funding. Faculty who involve themselves extensively in designing new curricula or promoting the partnerships required for an IEP place themselves and their careers in jeopardy. There is simply no motivation for faculty to become involved in such projects other than one's own personal commitment to its value. Unfortunately, this is not sufficient to support widespread change.

It is also true that significant innovation in any organization requires visionaries with the sustained passion and commitment necessary to bring the desired change to fruition, and the relative freedom to do so. An example is the case of Hermann Viets and John Grandin who rapidly became consumed by the idea of the IEP, and who both were in a position to act. Viets was dean of his college and thus unconstrained; Grandin had already been promoted to full professor and thus had the freedom to set his literary projects aside. Had they not met, had they not shared a common interest, had they not had the freedom to act, and had they not been successful opinion shapers, the IEP would not have come about. Change of this nature requires zealous champions, reliable partners, and leaders with credibility and the freedom to move forward.

Funding is another very real hurdle. Grandin and Viets needed funding to support travel as they visited companies in the U.S. and Germany to develop internships for their students. Grandin needed release time to commit to the project and to enable him, for example, to develop and offer separate introductory German courses for students of engineering. Funds to create promotional materials were also needed. Since there was no internal fund or seed money to get the program started, Grandin turned to the U.S. Department of Education and secured a FIPSE (Fund for the Improvement of Post Secondary Education) grant which supported all of the immediate needs and also lent prestige to the effort. Realistically, failure to find extramural support would have made the project undoable.

The lack of institutional commitment and support can also be a hurdle in the path of change. When the IEP was first in place, there was very little interest among URI administrators in international education, with the exception of Hermann Viets, thus leaving the full effort of the program in the hands of just a few faculty. Once the program had a longer track record of success and it had begun to attract attention and financial support from the private sector, however, the president took a greater interest in the project. Were we to start the program today, it would very 
likely find immediate administrative support, since the current president has designated global education as a major priority.

\section{Overcoming the Challenges}

We feel strongly that change such as is being suggested here must begin with recognition of the extent of the crisis in higher education today. Nothing will happen if the engineering faculty, for example, are blind to the challenges of the contemporary workplace, are unaware of the high disciplinary standards and competition set by colleagues across the globe, especially in Europe and Asia. Nothing will happen if faculty are comfortable in their departmental silos, convinced that their classes will always be filled for their traditional lectures. And nothing will happen if language faculty are allowed to teach to the very few students who enroll in their esoteric upper-level classes, which have no direct relationship to the world of employment. Faculty in all disciplines must open their eyes to the problems facing higher education today and must reassess the roles that they and their disciplines can or could play in preparing young people for meaningful careers.

Incentive for change can come from institutional leadership. Faculty need to be encouraged by their presidents, provosts, and deans to think about the university and its curriculum in a time of major change such as this. Institutional leadership is always "looking for stellar programs in which to invest". 27 A flagship program such as the IEP with its impressive success of garnering external support as well as several national awards both from the languages as well as from the engineering $\operatorname{side}^{28}$ provides such an investment opportunity. In addition, it gives the President, Provost and the collaborating deans a narrative, a story to tell which is unique and makes the university and its leadership stand out. Faculty should be encouraged to explore what students need to know in today's society, to rethink their places in the educational curriculum, and not to fear reaching out to untraditional partners. A president, for example, could offer challenge grants and seed money to explore opportunities with potential partners, to research potential funding sources, and to experiment.

As mentioned above, incentive for change could also come from the federal government in the form of a Morrill Act for the $21^{\text {st }}$ century. Just as President Lincoln reacted to the education needs for the age of industrialization, the current administration and Congress might seek to redefine the undergraduate curriculum

\footnotetext{
${ }^{27}$ Mark Roche, "Ensuring a Flourishing (German) Department: A Dean's Perspective," in German Quarterly 84.4 (Fall 2011) p. 416.

${ }^{28}$ The IEP and it directors have received awards from ABET (Educational Innovation Award), IIE (the Heiskell Award for Innovation in Study Abroad), ADFL and MLA (2012 Award for Distinguished Service in the Profession), NASULGC (Michael F. Malone Award), the German government (Federal Cross of Honor), the German Academic Exchange Service (DAAD Alumni Award for International Exchange), AATG (Outstanding German Educator), NAFSA (Senator Paul Simon Spotlight Award for Campus Internationalization)
} 
for the age of globalization. There might, for example, be a certification process resulting in special funding for universities that could, for example, be certified as Morrill 2012 universities. Land Grant was a concept for its time, just as Sea Grant became a concept for its time in 1966. Space Grant in 1988, and Sun Grant in 2003). Morrill 2012 institutions would redefine liberal education by creative curricula through which students would acquire the benefits of both a technical/professional and liberal arts education. They would possess the skills to thrive in an era of rapid change, defined by modern technology and globalization.

With or without federal support, higher education leaders should and can take specific action to drastically change the rewards system for faculty, making it possible to commit themselves to programmatic ventures such as the IEP without endangering their university careers. One might, for example, allow faculty to pursue different tracks, with some focused more on teaching than research, with others more on research, and others on entrepreneurial program building. Given these options, one might even build flexibility into the system so that a research faculty member could, for example, devote five years to the teaching track or the administrative track. Such five-year blocks could be defined by contract, with very clear duties and expectations. All of these professional strands would be acceptable as steps toward tenure and promotion, assuming that certain predefined standards are met.

Administrators should also provide more than lip service for interdisciplinary teaching and programming. It could be made much easier for faculty to have joint appointments, and for programs such as the IEP to be at home in both a College of Engineering and a College of Arts and Sciences. Deans should be prepared to cofund projects which are in the interest of both colleges. They should be prepared to jointly mentor and evaluate faculty participating in cross-disciplinary programs.

The administration should also be prepared to help faculty overcome university bureaucracies which are, by design, only equipped to deal with the status quo. Faculty can easily be discouraged by institutions which do not embrace attempts to do things differently and have little room for experimentation in the curriculum. The IEP survived by persisting in the face of resistance when proposing, for example, two degrees (BA/BS) in five years, or attempting to streamline the general education program for IEP students, or creating dual degree masters programs with partner schools abroad, or even accepting financial support from the People's republic of China. It is an unfortunate reality that institutions often say "no" in the face of common sense proposals, when they should be saying: "Now this makes sense. How can we make this happen?" Would it not be possible to appoint an innovation board, i.e., a group of faculty and administrators who are pledged to help their school's academic entrepreneurs?

To encourage cross-disciplinary teaching, administrators should require all faculty to participate in general education curricula. It would be important, for example, for engineering faculty to offer engineering courses for non-science majors, or 
engineering courses for an engineering minor or engineering Bachelor of Arts degree. Science faculty should do the same, as should pharmacy and medical school faculty, and law and business faculty as well. No humanities or social science student should be allowed to graduate without sufficient background in science and technology to comprehend and appreciate those things which drive our economy and impact our daily lives. Likewise, no engineering student should be allowed to graduate without exposure to engineering as practiced abroad and through global teamwork, and without demonstrating the acquisition of strong communication skills, problem-solving skills and a commitment to lifelong learning.

Administrators and faculty should be continually networking with leaders from the private sector who will be hiring their graduates. New curricula should be developed with the advice and counsel of leaders from business and industry, and the latter should also be expected to help finance the education of their future employees. Students of our programs should be able to find appropriate internships where they can learn but also receive valuable feedback. If such a network is active, we should never hear that our education system is not producing graduates with the skills needed for the workplace and for the $21^{\text {st }}$ Century. And we should no longer hear that $50 \%$ of our graduates are unemployed or underemployed. 